\title{
Epidemiologic profile of the suicidal intoxication in the Tadla- Azilal region, Morocco
}

\author{
${ }^{1}$ s. El Khaddam, ${ }^{1}$ a. Soulaymani ${ }^{2}$ l. Ouammi, ${ }^{2}$ m. Windy, ${ }^{1}$ f. Hadrya, \\ ${ }^{1}$ a. Khadmaoui, ${ }^{1}$ a. Mokhtari, ${ }^{2,3}$ r. Soulaymani-Beincheikh \\ ${ }^{I}$ laboratory Of Genetics And Biometry, Faculty Of Sciences, University Ibn Tofail, Kenitra, Morocco \\ ${ }^{2}$ anti Poison And Pharmacology Center Of Morocco, Rabat, Morocco, ${ }^{3}$ faculty Of Medicine And Pharmacy, \\ University Of Mohamed V, Rabat, Moroccosafaa El Khaddam Laboratory Of Genetics And Biometry, Faculty \\ Of Sciences, University Ibn Tofail, Kenitra 1400, Morocco.
}

\begin{abstract}
The region of Tadla-Azilal is one of the Moroccan regions that are mostly affected by the voluntary intoxications with a suicidal aim, while the exact dimensions of this phenomenon are still poorly identified. This study seeks to describe the characteristics related to this kind of intoxication, in order to understand the posed problem and to reduce the morbi-mortality which results from it. A retrospective study was carried out on the reported suicidal cases of intoxications in the period between 2000 and 2008, at the Poison and Pharmacology Center of Morocco (CAPM). During the study period, the Tadla-Azilal region had registered 1033 cases of suicidal intoxications, of which 38 cases died, namely a fatality of $3.7 \%$. The average age of the patients was 28,94 $\pm 15,92$ years. The sex-ratio (woman/man) was 1.69. The relation study showed a strong link between the favorable evolution and the female adolescents on the one hand, and between the unfavorable evolution and the male adults on the other hand. According to the results of the relative risk evaluation, the voluntarily intoxicated patients, by taking the pesticides, had presented four times the risk to progress towards death compared to other incriminated products (RR=4,26; CI95\%: 1,85-9,81).
\end{abstract}

KEY WORDS: intoxication, suicide, Rrsk factors, Tadla-Azilal, Morocco.

\section{INTRODUCTION}

Nowadays, suicides and suicide attempts pose a serious problem of public health, according to World Health Organization [1]. At the international level, suicide represented 1,8\% of the total disease burden in 1998 . However, in 2020, this proportion could reach 2,4\% in countries with market economies or in the former socialist economies [1]. The highest mortality rates are noticed in Eastern Europe such as in Belarus, with 41, 5 per 100000 inhabitants, and in Lithuania with 51,6 per 100000 inhabitants. In return, the lowest rates have been noticed mainly in Latin America (4,5 per 100000 inhabitants in Colombia), or also in some Asian countries (2,1 per 100000 inhabitants in Thailand). In Western Europe, North America or in some parts of Asia, the rates are between these two ends (France: 20 per 100000 inhabitants, Canada: 15 pour 100000 inhabitants, Japan: 19,5 per 100000 inhabitants, and Germany: 14,3 per 100000 inhabitants.) [2]. In Morocco, and according to the Anti Poison and Pharmacology Center of Morocco (CAPM), 17206 cases of suicide and suicide attempts, by taking toxics voluntarily, were reported during the period between 1980 and 2007, namely $92,4 \%$ of all cases of voluntary intoxication [3]. The Tadla-Azilal region is widely known by the expansion of this toxicological pathology whose exact dimensions remain poor identified. This study seeks to describe the characteristics relating to patients, to suspected toxics and to intoxication, as well as to determine risk factors that may influence the evolution of the patients' health status, in order to reduce the morbi-mortality caused by suicidal intoxications in the study area.

\section{Patients and methods}

Study site

The Tadla-Azilal region is geographically located in the West-central Morocco. Its surface area is 16 $996 \mathrm{~km}^{2}$; it represents $3,2 \%$ of the national territory; Its population is estimated at 1479000 inhabitants in 2004, namely $4,85 \%$ of the overall population [4]. At the administrative level, the region is divided into two provinces: Beni Mellal and Azilal (figure 1). 


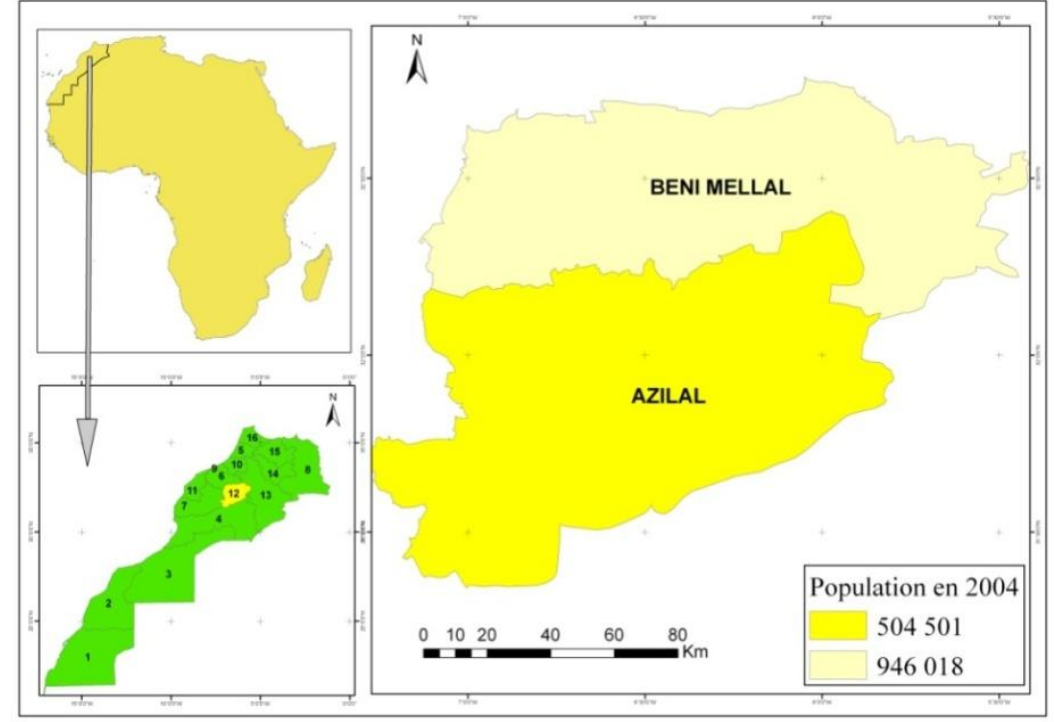

Fig.1: Geographical location of the region Tadla-Azilal in Morocco

\section{Sources of information:}

The data carriers used in this study are the toxicovigilance forms (declaration forms), that are filled in by the doctor or the nurse in charge of the patient at a health facility in the region, and the medical records that are organized to serve the toxicological information at the CAPM.

\section{Studies parameters:}

The studied characters concern the epidemiological characteristics of the intoxicated patients (age, sex, origin), clinical (symptoms, gradation) and the characteristics of the toxic products.

The influence of these different factors on the evolution of the patient's health status will be also discussed in this work. This evolution will correspond here with the gradation (the degree of case severity). The used score is the « Poisoning Severity Score (PSS) » [5], defined

+ Level 0: No functional or physical signs;

+ Level 1: Minor symptoms, transient and self-limiting;

+ Level 2: Marked or persistent symptoms;

+ Level 3: Severe or life threatening symptoms, and;

+ Level 4: Fatal intoxication.

\section{Methodology:}

This work is a retrospective study of all the reported suicidal intoxication cases, during the period between 2000 and 2008 in Tadla-Azilal region, collected from the Anti Poison and Pharmacology Center of Morocco.To indentify links between these variables and the evolution of the patients (cure, death), we used the chi-square test $(\chi 2)$ of contingency. To view the existing links between the different examined variables and the evolution, the principal component analysis (PCA) was conducted. The calculation of the relative risk allowed us to indentify the degree of association between some variables and the evolution of patients.

\section{RESULTS}

During the period between 2000 and 2008, 1033 cases of suicidal intoxication in the Tadla-Azilal region were reported.The distribution of the suicidal intoxications cases, according to epidemiological characteristics of the studied population, is shown in (Table I). 
Table I : Epidemiologic characteristics of the studied population

\begin{tabular}{|c|c|c|c|c|c|c|}
\hline \multirow[t]{2}{*}{ Studied variables } & \multirow[t]{2}{*}{ Number of cases } & \multirow[t]{2}{*}{ Frequency $(\%)$} & \multicolumn{3}{|c|}{ Évolution } & \multirow[b]{2}{*}{ Specific fatality (\%) } \\
\hline & & & Cure & Death & Unknown & \\
\hline \multicolumn{7}{|l|}{ Sex } \\
\hline Female & 649 & 62,83 & 405 & 20 & 224 & 3,08 \\
\hline Male & 384 & 37,17 & 227 & 18 & 139 & 4,69 \\
\hline Unknown & - & - & - & - & - & - \\
\hline Total & 1033 & 100,00 & 632 & 38 & 333 & 7,77 \\
\hline \multicolumn{7}{|l|}{ Age group } \\
\hline Children & 50 & 4,84 & 33 & 1 & 16 & 2,00 \\
\hline Adolescents & 326 & 31,56 & 213 & 7 & 106 & 2,15 \\
\hline Adults & 645 & 62,44 & 379 & 30 & 236 & 4,65 \\
\hline The elderly & 2 & 0,19 & 2 & - & - & - \\
\hline Unknown & 10 & 0,97 & 5 & - & 5 & - \\
\hline Total & 1033 & 100,00 & 632 & 38 & 363 & 8,80 \\
\hline \multicolumn{7}{|l|}{ Environment } \\
\hline Urban & 318 & 30,78 & 187 & 7 & 124 & 2,20 \\
\hline Rural & 355 & 34,37 & 201 & 19 & 135 & 5,35 \\
\hline Unknown & 360 & 34,85 & 244 & 12 & 104 & 3,33 \\
\hline Total & 1033 & 100,00 & 632 & 38 & 363 & 10,88 \\
\hline \multicolumn{7}{|l|}{ Province } \\
\hline Beni Mellal & 1003 & 97,09 & 607 & 38 & 358 & 3,79 \\
\hline Azilal & 30 & 2,91 & 25 & - & 5 & - \\
\hline Unknown & - & - & - & - & - & - \\
\hline Total & 1033 & 100,00 & 633 & 38 & 363 & 3,79 \\
\hline \multicolumn{7}{|l|}{ Place } \\
\hline House & 984 & 95,26 & 609 & 38 & 337 & 3,79 \\
\hline Work & 14 & 1,35 & 7 & - & 7 & - \\
\hline Public & 13 & 1,26 & 8 & - & 5 & - \\
\hline Unknown & 22 & 2,13 & 8 & - & 14 & - \\
\hline Total & 1033 & 100,00 & 632 & 38 & 363 & 3,79 \\
\hline \multicolumn{7}{|l|}{ Clinical signs } \\
\hline Digestive & 706 & 68,34 & 448 & 32 & 226 & 4,53 \\
\hline Neurological & 48 & 4,65 & 36 & 1 & 11 & 2,08 \\
\hline cardiovascular & 13 & 1,26 & 9 & 1 & 3 & 7,69 \\
\hline Respiratory & 114 & 11,06 & 75 & 3 & 35 & 2,63 \\
\hline General & 2 & 0,20 & 1 & - & 1 & - \\
\hline Inconnu & 150 & 14,52 & - & 1 & 149 & 0,67 \\
\hline Total & 1033 & 100,00 & 569 & 38 & 425 & 17,60 \\
\hline \multicolumn{7}{|l|}{ Level } \\
\hline Level 0(None) & 10 & 0,97 & 7 & - & 3 & - \\
\hline Level 1(Minor) & 19 & 1,84 & 13 & - & 6 & - \\
\hline Level 2(Moderate) & 875 & 84,70 & 579 & - & 296 & - \\
\hline Level 3(Severe) & 58 & 5,62 & 31 & - & 27 & - \\
\hline Level 4(Fatal) & 38 & 3,68 & - & - & - & - \\
\hline Unknown & 33 & 3,19 & 6 & - & 27 & - \\
\hline Total & 1033 & 100,00 & 636 & 38 & 359 & 3,79 \\
\hline
\end{tabular}

In the study area, these intoxications had affected some groups of the population, mainly the adults whose age is between 20 and 74 years, with $62,44 \%$ of cases. The highest fatality rates were also noticed in adults $(4,65 \%)$. The average age of the intoxicated people was $28,94 \pm 15,92$ years.According to the analysis results, women had frequently attempted to commit suicide (Sex-ratio=1,69; $\chi^{2}=67,98 ; p<0,001$ ) unlike men ; most were able to take their own lives. The fatality rates being $(4,69 \%)$. The intoxication cases coming from rural and urban areas were affected in the same way $\left(\chi^{2}=2,03 ; p=0,15\right)$ The geographical distribution of the intoxication cases show that the two provinces were affected, with a maximum of reports registered in the province of Beni Mellal (97,1\%). Thirty eight deaths were reported in the province of Beni Mellal against zero deaths in the province of Azilal. Houses were the main places of suicides and attempted suicides. The majority of patients had gastrointestinal symptoms, associated or not associated with respiratory, neurological and cardiovascular signs. However, the highest fatality rate was noticed in the patients with cardiovascular problems $(7,69 \%)$.

Nevertheless, lethality was high in subjects with acute diarrhea $(13,18 \%)$ due to possible dehydration. Gastric lavage was prescribed to $99,1 \%$ of subjects who were taken charge of. The severity of the intoxication was often moderate (level 2). Among the 1000 patients for whom the evolution was known, 38 cases had died, namely a fatality of $3,8 \%$. 
The number of reports and the specific fatality, according to the families of the incriminated objects, is shown in (figure 2):

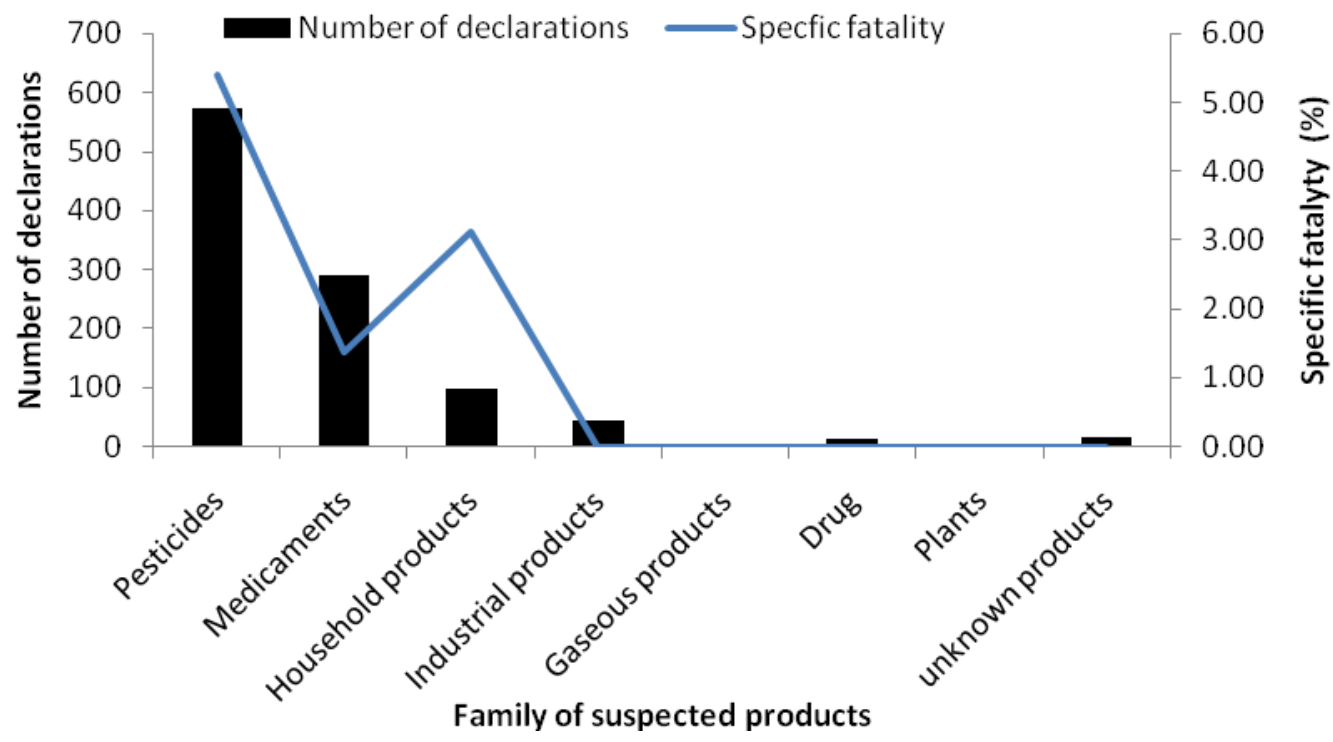

Fig. 2: Distribution of the cases of the suicidal intoxications and specific fatality according to the suspected toxic products

The suicidal intoxications linked to pesticides had recorded the highest number of reports in the region, with 55,57\% of cases. Drug intoxications ranked second, followed by intoxications linked to household products $(27,98 \%$ and $9,29 \%$ respectively). The most major fatality was noticed in those who were intoxicated by pesticides $(5,4 \%)$, followed by those who were intoxicated by the household products and the medicaments, with a fatality of $3,13 \%$ and $1,38 \%$ respectively.

The links, found between toxic products, sex, age groups and the evolution of patients, are shown in (figure 3 )

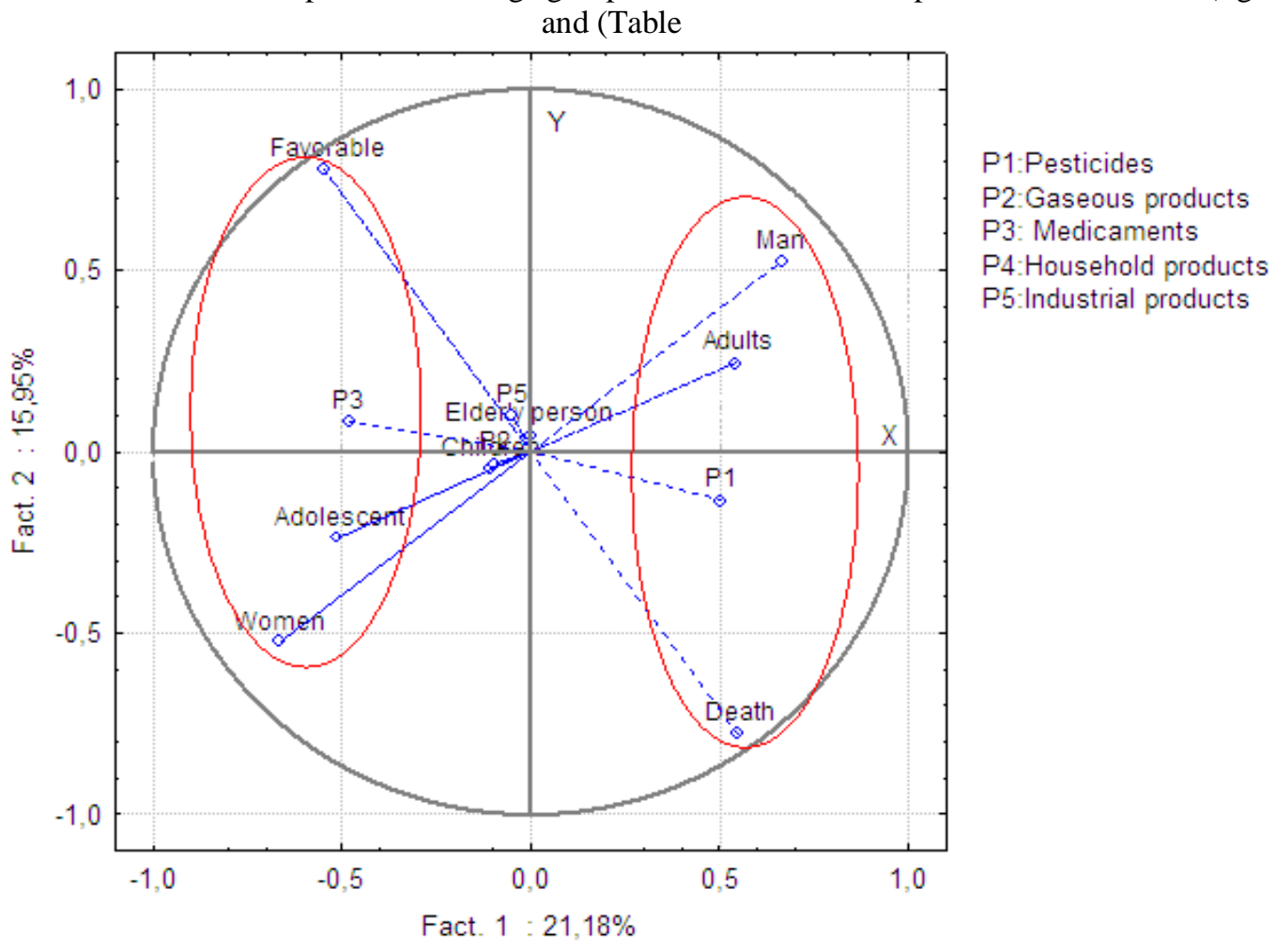

II).

Fig.3: Projection of sex, age groups, toxic products and the evolution on the factorial experiment 
Table II: Link of the factors studied on the weight of the variables

\begin{tabular}{ccccc}
\hline & Women & Men & Favorable & Death \\
\hline Adolescent & 0,13108 & $-0,13108$ & 0,07815 & $-0,07815$ \\
Adult & $-0,14747$ & 0,14747 & $-0,09027$ & 0,09027 \\
The elderly & $-0,01542$ & 0,01542 & 0,01378 & $-0,01378$ \\
Children & 0,04928 & $-0,04928$ & 0,02881 & $-0,02881$ \\
Women & 1 & -1 & 0,05557 & $-0,05557$ \\
Men & -1 & 1 & $-0,05557$ & 0,05557 \\
products & $-0,14244$ & 0,14244 & $-0,1424$ & 0,1424 \\
Gaseous products & $-0,0424$ & 0,0424 & 0,01689 & $-0,01689$ \\
Medicaments & 0,13502 & $-0,13502$ & 0,11311 & $-0,11311$ \\
Household products & 0,09427 & $-0,09427$ & 0,01357 & $-0,01357$ \\
Industrial products & 0,02446 & $-0,02446$ & 0,04749 & $-0,04749$ \\
Favorable & 0,05557 & $-0,05557$ & 1 & -1 \\
Death & $-0,05557$ & 0,05557 & -1 & 1 \\
\hline
\end{tabular}

The two first areas contribute with $34,32 \%$ in the total variation of fatal toxic products, of sex, of signs and age groups depending on the evolution.According to the first area (19,56\%), we notice a strong association between men and the age group of adults of side $\mathrm{X}+$, and between women and the age group of adolescents in the opposite part. Along the second area $(15,95 \%)$, we notice a less strong association between the use of medicaments and the favorable evolution of side $\mathrm{Y}+$ and between agricultural products and the unfavorable evolution in the opposite part. These results reveal a strong relation between the use of pesticides by male adults and the progression towards death on the one hand, and between the use of medicaments by female adolescents and the favorable evolution in the other hand.

To determine the factors that influence life threatening of patients, we calculated the chi-square and the relative risk. The results of the analysis are shown in (table III).

Table III: / Study of the studied variables effect on the patients' evolution

\begin{tabular}{|c|c|c|c|c|c|c|c|c|c|}
\hline Variables & Modalities & Numbers & Cure & Death & Unknown & $\chi^{2}$ & $\mathrm{P}$ & (RR) & CI95\% \\
\hline \multirow{2}{*}{ Sex } & Female & 649 & 405 & 20 & 224 & \multirow{2}{*}{2,02} & 0,15 & \multirow{2}{*}{1,61} & \multirow{2}{*}{$0,83-3,09$} \\
\hline & Male & 384 & 227 & 18 & 139 & & \multirow[b]{2}{*}{0,5} & & \\
\hline \multirow{3}{*}{ Age } & Children & 50 & 33 & 1 & 16 & 0,51 & & 0,48 & $0,06-3,67$ \\
\hline & Adolescent & 326 & 213 & 7 & 106 & 3,91 & 0,05 & 0,43 & $0,19-1,01$ \\
\hline & Adult & 645 & 379 & 30 & 236 & 5,18 & 0,02 & 2,45 & $1,11-5,44$ \\
\hline \multirow{2}{*}{ Origin } & Rural & 355 & 201 & 19 & 135 & \multirow{2}{*}{4,43} & 0,04 & \multirow{2}{*}{0,40} & \multirow{2}{*}{$0,16-0,96$} \\
\hline & Urban & 318 & 187 & 7 & 124 & & & & \\
\hline \multirow{3}{*}{ Products } & Pesticides & 513 & 297 & 31 & 186 & 13,46 & $<0,01$ & 4,26 & $1,85-9,81$ \\
\hline & $\begin{array}{c}\text { Household } \\
\text { products }\end{array}$ & 79 & 56 & 3 & 20 & 0,13 & 0,7 & 0,80 & $0,24-2,68$ \\
\hline & Medicaments & 250 & 187 & 4 & 60 & 8,49 & 0,004 & 0,24 & $0,08-0,67$ \\
\hline
\end{tabular}

We notice from these results that the age group of adults is a factor that represents a significant association with deaths $(\mathrm{RR}=2,45$; IC95\%=1,11-5,44). In addition to that, the patients intoxicated by the pesticides had four times more risks to progress towards death $(\mathrm{RR}=4,26$; $\mathrm{IC} 95 \%=1,85-9,81)$.

\section{DISCUSSION}

Our study involves 1033 cases of suicide attempts and suicides that were reported at the Tadla-Azilal region. This number is facing a problem of completeness. In fact, many victims were not sent to a hospital. In our series, the average age of patients was $28,94 \pm 15,92$ years. 
The suicidal intoxications affect both sexes with a female predominance, and this corresponds with several publications [6, 7]. In France, the number of suicides is 12000 per year. This number exceeds that of deaths due to road accidents. These 12000 suicides primarily involve men. Men commit suicide two times more than women [8].Paradoxically, women are much more likely to attempt suicide than men, but the increasing fatality concern men. Studies found out that suicide is a male act $[8,9]$, even if some rare regions make the exception: the China case $[10,11]$. This can be explained by the fact that men move into action easily, they do not seek to express their anxiety, their regret or share them. On the other hand, studies [12,13] justified this phenomenon by the fact that women are normally far from the labor life, and men have more financial and social problems which may lead to serious worries and depressions. Such psychological pressures in the population may be the cause of the increase in suicide attempts.

The subjects treated in our study were mainly adults. As indicated in the bibliography, adults are often confronted with voluntary intoxications for socio-economic reasons [14, 15,16].Suicide in adolescents affects the collective consciousness by its tragic and socially "inacceptable", aspect, although it is less common than in adults and the elderly [2]. According to our results, adolescents represent a minority, which corresponds with the bibliography [17,18]. In fact, there exists a clear relation between depression and suicide attempt during the adolescence, even if these two concepts do not meet with each other totally [19,20]. Moreover, 4,84 \% of patients were children, a non-reduced frequency. According to [21], suicide in children from the age 7 to 15 years had represented $3,8 \%$ of causes of death in 2008 .

This study also revealed that the suicidal intoxications linked to pesticides, including organophosphates, had registered the highest number of declarations in the region, with 55,57 \% of cases and a specific fatality of $5,7 \%$. This may be explained by the availability of these products in the rural areas, namely the fields and the farmlands of the region. The chemical class of pesticides, implicated in the voluntary intoxications, varies from a country to another, but that of organophosphates is commonly reported [22,23]. In Morocco, 1067 cases of suicide attempts by the pesticides were registered in the period between 1992 and 2007 [24]. This may be due to the fact that these potential toxic products circulate easily and are largely available due to deficiency and non-enforcement of regulations. Besides, the Tadla-Azilal region is one of the most wellknown Moroccan regions for its agricultural potential and the large use of these toxic products. On the other hand, males were more exposed to pesticides. The given reasons, that justify the going into the act, are many, but the availability of pesticides is the main reason nevertheless. Secondly, the fact that men work in the farmlands more than women, which makes men thus more exposed to these products. Moreover, men seek the most efficient toxic to commit suicide, and in these conditions the pesticides is the most useful way. According to our data, the voluntary ingestion of medicaments occupied the second position, with 27,98\% of cases. On the other hand, our results showed a significant likeness between voluntary intoxication by drug products and the female sex. These data are consistent with the results described in the bibliography $[16,25,26]$.

\section{CONCLUSION :}

Being a serious problem of public health, suicide and suicide attempts require our attention as well as its prevention, its control, which represents a less easy task. In our data series, it appears that fatality was linked mainly to voluntary ingestion of pesticides. In the commercial level, sale, distribution and the release of phytosanitary products must be regulated by the state. In the medical level, the health professionals must know the means of immediate treatment in intensive care units, they must be familiar with the clinical picture and the potential danger of this type of intoxication, and set up a more efficient prevention in order to minimize the frequency and the severity of intoxications in this region.

\section{BIBLIOGRAPHIC REFERENCES}

[1] Organisation Mondiale de la Santé (OMS), La prévention de suicide, indications pour professions de santé primaire, Genève, 2002 .

[2] A. Batt, A. Campeon, D. Leguay et P. Lecorps, Épidémiologie du phénomène suicidaire : complexité, pluralité des approches et prévention, 5-14.

[3] L. Ouammi, N. Rhalam, R. Aghandous, I. Semlalli, M. Badri, G. Jalal, S. Benlarabi, A. Mokhtari, A. Soulaymani, R. Soulaymani-Beincheikh, Profil épidémiologique des intoxications au Maroc de 1980 à 2007, Toxicologie Maroc, $2009,1,8-13$.

[4] Haut-Commissariat au Plan, Recensement général de la population et de l'habitat de 2004, Caractéristiques démographiques et socio-économiques région de Tadla-Azilal, 2006, 12

[5] H.E. Persson, G.K. Sjoberg, J.A. Haines et J. Pronczuk De Garbino, Indice de gravité de l'intoxication, Année d'intoxication aiguë, Clin Toxicol, 1998 36, 205-213.

[6] C. Delamare, Y. Martin et C.Blanchon, Tentatives de suicide chez l'enfant de moins de 13 ans, Neuropsychiatrie de l'Enfance et de l'Adolescence, 2007, 55, 41-51.

[7] F. Staikowsky, F. Theil et S. Candella, Evolution des médicaments utilisés dans les intoxications médicamenteuses volontaires examinées aux urgences, Presse Med, 2005, 34, 846. 
[8] C.H. Cantor, Suicide in the western world, in K. Hawton, K. Van Heeringen (Eds.), The international handbook of suicide and attempted suicide, Chichester: JohnWiley and sons, 2000, 9-28.

[9] V. Bellamy et M.C. Mouquet, Suicides et tentatives de suicide en France - Direction de la Recherche des Etudes de l'Évaluation et des Statistiques, Etudes et résultats, 2006, 488, 1-8.

[10] C. Baudelot et R. Establet, Suicide l'envers de notre monde, Paris, Seuil, 2006.

[11] M. Nock, G. Borges, E.J. Bromet, C.B. Cha, R.C. Kessler et S. Lee, Le fardeau des troubles manteaux, Epidemiologic reviews, $2008,30(1), 1-14$.

[12] H. Oguzturk, M. Gokhan Turtay, E. Pamukcu et O. Ciftci, Demographic features of acute drug poisoning admitted to Inonu university hospital in Malatya, Turkey, Scientific research and essays, 2010, 5 (18), 2761-2767.

[13] B.M. Samake, Y. Coulibaly, A.I. Dramé, M.A. Cissé, M.Z. Doumbia, F. Sanou et A. Diallo, Profil épidémiologique des intoxications aiguës au C.H.U, Gabriel Toure, Mali Médical, 2011, Tome XXVI, (3), 34-36.

[14] J.C. De Miguel-Bouzas, E. Castro-Tubio, A.M. Bermeio-Barreraet, P. Fernandez-Gomez et M.J. Tabernero-Duque , Epidemiological study of acute poisoning cases treated at a Galician hospital between 2005 and 2008, Adicciones, 2012, 24(3), $239-46$.

[15] R. Cremer et M. Mathieu-Nolf, Epidémiologie des intoxications de l'enfant, Archives de pédiatrie, 2004, 11(6), 677-679.

[16] F. Staikowsky, D. Uzan, N. Grillon, F. Pevirieri et A.Hafi, Intoxications médicamenteuses volontaires reçues dans un serviced'accueil des urgences, Presse Médicale, 1995, Vol 24(28), 1296-1300.

[17] L. Toilabiya, A. Soulaymani, D.Benali, H. Hami, L. Ouammi, A. Mokhtari, N. Rhalem et R. Soulaymani Profil épidémiologique des intoxications dans la région de Tanger-Tétouan au Maroc, Antropo, 2012, 26, 49-57.

[18] N. Attazagharti, A. Soulaymani, L. Ouammi, A. Mokhtari, R. Bencheikh Soulaymani, Intoxications médicamenteuses et facteurs de risque influençant l'évolution des patients, Antropo, 2009, 19, 33-39.

[19] M. Gispert et K.Wheeler, Suicides de l'adolescent scolarisé, Une étude épidémiologique chez les jeunes scolarisés (12-20 ans), Ann Psychiatr, 1998, 13, 16-23.

[20] C. Mouttia, W. Fischer et F. Ladame, Caractéristiques cliniques d'une cohorte d'adolescents suicidants, résultats préliminaires d'une étude prospective, in F. Lkadame, J. Ottino, C. Pawlak (Ed.), Adolescence et suicide, (Paris: Masson, 1995) 67-73.

[21] S. Achour, A. Khatabi, N. Rhalem, L. Ouammi, A. Mokhtari, A. Soulaymani et R. Soulaymani Beincheikh, L'intoxication par les pesticides chez l'enfant au Maroc : profil épidémiologique et aspects pronostiques (1990-2008), Santé publique, 2011, 23 (3), 195-205.

[22] D. Gunnell, M. Eddleston, Suicide by intentional ingestion of pesticides: a continuing tragedy in developing countries, Int $J$ Epidemiol, 2003, 32, 902-909.

[23] F. Davanzo, A. Travaglia et M. Chiericozzi , V Dimasi , F. Sesana ,L. Faraoni L, L. Settimi L et T.J Ballard , Pesticide poisoning referred to the Poison Center of Milan in 1995-1998, Ann Ist Super Sanita, 2001, 37(2), 127-31.

[24] N. Rhalem, A. Khattabi , S. Achour, A. Soulaymani et R. Beincheikh, Facteurs prédictifs de gravité de l'intoxication aux pesticides, Expérience du Centre Antipoison du Maroc, Annales de Toxicologie Analytique, 2009, 21(2), $79-84$.

[25] S. Halayem, A. Bouden, S. Othman, M.B. Halayem, Profil du suicidant en population clinique, une expérience tunisienne, Neuropsychiatrie de l'enfance et de l'adolescence, 2010, 58,120-12

[26] N. Badrane, F. Abadi , L. Ouammi et R. Bencheikh Soulaymani, Intoxications médicamenteuses au Maroc, Données du Centre Anti Poison du Maroc (1980-2008), Toxicologie Maroc, 2010, 4(7), 7-10. 